\title{
8
}
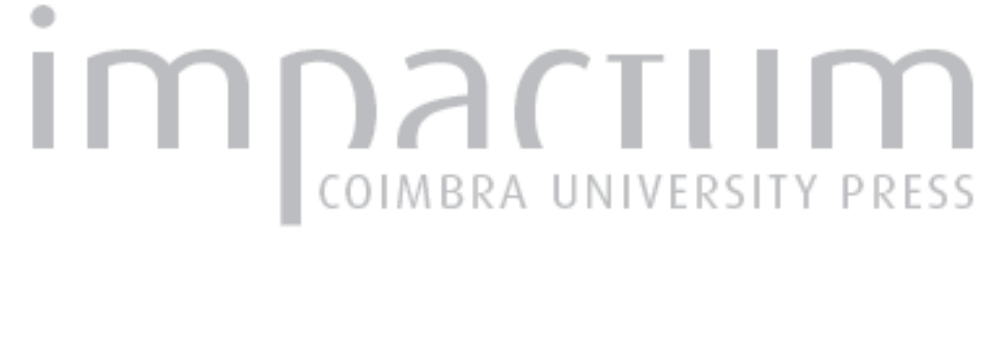

\section{Em torno do ensaio Arte e escatologia de Eudoro de Sousa}

\section{Autor(es): Menon, Walter}

Publicado por: Annablume Clássica; Imprensa da Universidade de Coimbra

URL persistente:

URI:http://hdl.handle.net/10316.2/24347

DOI:

DOI:http://dx.doi.org/10.14195/1984-249X_8_11

Accessed : $\quad$ 26-Apr-2023 08:27:10

A navegação consulta e descarregamento dos títulos inseridos nas Bibliotecas Digitais UC Digitalis, UC Pombalina e UC Impactum, pressupõem a aceitação plena e sem reservas dos Termos e Condições de Uso destas Bibliotecas Digitais, disponíveis em https://digitalis.uc.pt/pt-pt/termos.

Conforme exposto nos referidos Termos e Condições de Uso, o descarregamento de títulos de acesso restrito requer uma licença válida de autorização devendo o utilizador aceder ao(s) documento(s) a partir de um endereço de IP da instituição detentora da supramencionada licença.

Ao utilizador é apenas permitido o descarregamento para uso pessoal, pelo que o emprego do(s) título(s) descarregado(s) para outro fim, designadamente comercial, carece de autorização do respetivo autor ou editor da obra.

Na medida em que todas as obras da UC Digitalis se encontram protegidas pelo Código do Direito de Autor e Direitos Conexos e demais legislação aplicável, toda a cópia, parcial ou total, deste documento, nos casos em que é legalmente admitida, deverá conter ou fazer-se acompanhar por este aviso.

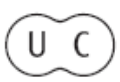


jan.2012

issn $2179-4960$

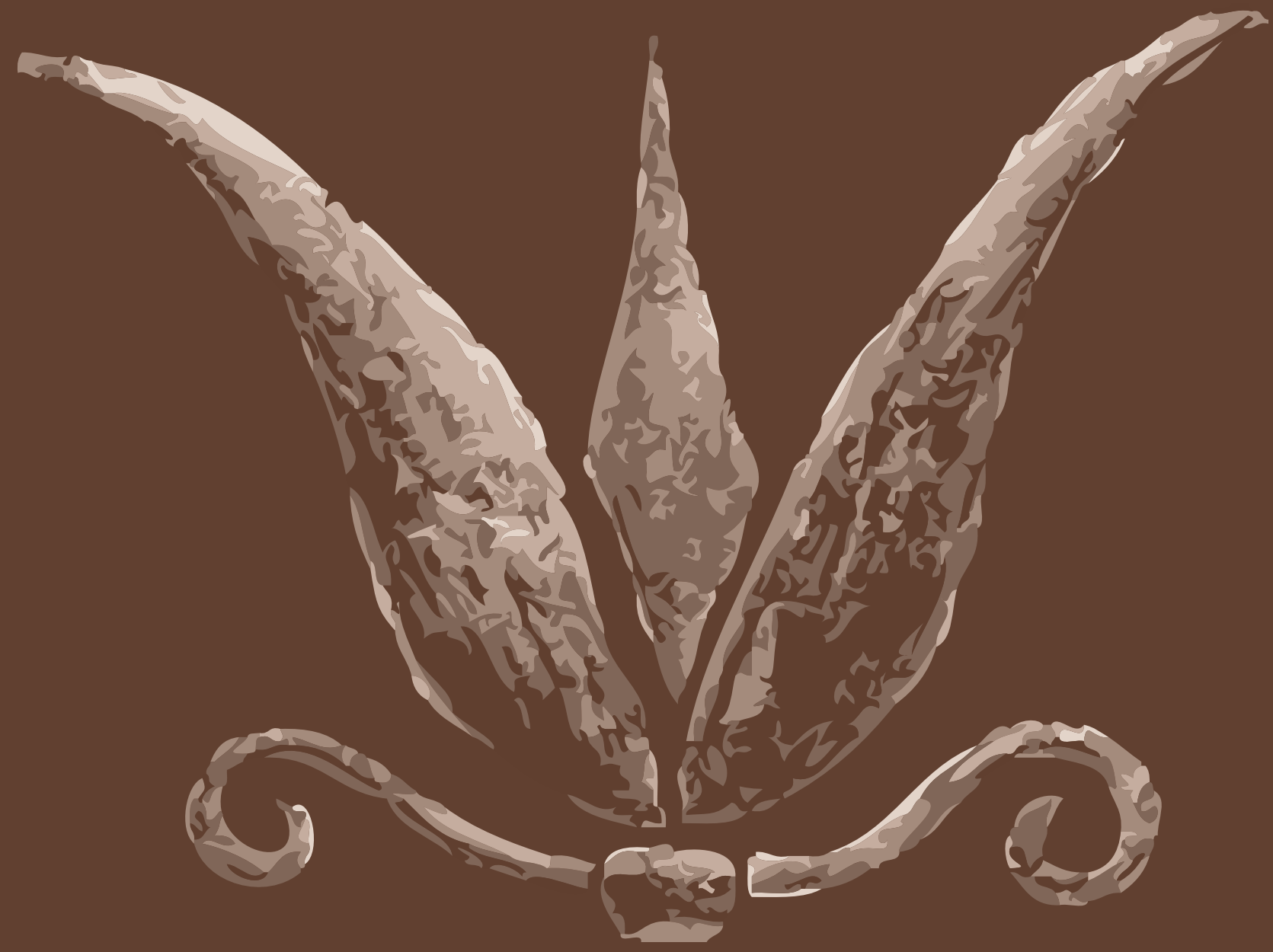

R E V I S T A
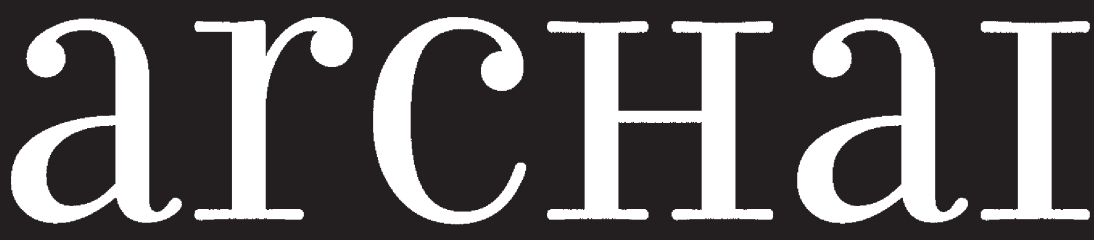

AS ORIGENS DO PENSAMENTO OCIDENTAL

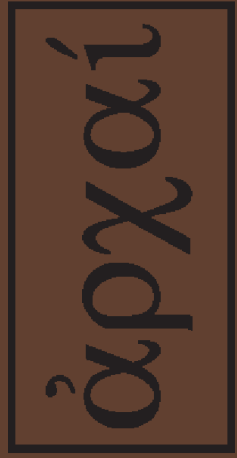

ARCHAI JOURNAL: ON THE ORIGINS OF WESTERN THOUGHT
arcHaI

AS ORIGENS DO PENSAMENTO OCIDENTA.

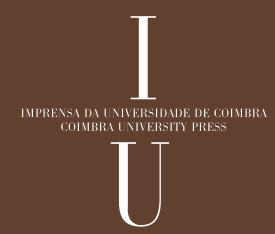

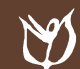




\section{EM TORNO DO ENSAIO ARTE E ESCATOLOGIA DE EUDORO DE SOUSA}

MENON, W. (2012). “Em torno do ensaio Arte e escatologia de Eudoro de Sousa". Archai n. 8, jan-jun 2012, pp. 101-107.

RESUMO: Este texto pretende apresentar o pensamento filosófico de Eudoro de Sousa a partir de suas concepções estéticas, notadamente aquelas apresentadas no ensaio Arte e Escatologia da obra Dioniso em Creta.

PALAVRAS-CHAVES: Mito, arte, origem, mitosofia.

ABSTRACT: This paper presents the philosophy of Eudoro de Sousa from the viewpoint of his aesthetic conceptions, particularly those presented in the essay Arte e Escatologia, published along with his work Dioniso em Creta.

KEY WORDS: Myth, Art, origin, mitosophy.
* Professor adjunto do Departamento de Filosofia da UFPR. Curitiba. Brasil.
Walter Menon*

0 propósito deste texto é de me colocar à disposição da linguagem e do projeto de Eudoro de Sousa entendido como o saber das origens, ou uma mitosofia, e de pensá-lo como uma estética. Creio encontrar no texto de Eudoro o percurso de uma estética que se resolve e envolve o próprio pensamento. Se estética há na obra de Eudoro, ela não se resume a uma tentativa de categorizar o que seja a experiência do belo, nem mesmo a tecer observações aqui e acolá sobre a relação da arte com a filosofia e com a mitologia. Isto seria apenas verdade dentro de uma leitura programática da obra do filósofo. 0 que pretendo no decorrer deste ensaio é apresentar, ou melhor, deixar surgir, no itinerário de uma possível leitura de Eudoro, uma estética no sentido de um poetizar do pensamento. Há, entretanto, um ponto de partida: o texto de Arte e Escatologia. Talvez o único, em toda a obra de Eudoro, dedicado diretamente à questão da estética, este ensaio, ao meu ver, sintetiza, mas não esgota o tema da arte em Eudoro.

Eudoro não produziu uma estética no sentido de uma disciplina filosófica ou de uma teoria da arte, repito. Sua obra estaria mais próxima, do que eu chamaria, uma poética, isto é, um processo de invenção no qual a dimensão do sensível é primordial, mas que não se esgota aí envolvendo também aquela outra do processo lógico-discursivo. 0 pensar 
de Eudoro não é uma filosofia que exclui, mas um encaminhar de um logos que inclui.

Disse, no começo, me colocar à disposição do texto eudoriano para, nele, deixar aparecer o sentido de uma estética, sem a ela reduzi-lo. Que outra maneira haveria de nos aproximarmos, coerentemente, da obra deste pensador, senão nos situando na esfera do seu convite amoroso? Um convite para uma escuta das origens, para o encontro com um horizonte, no qual, após o cansaço de ter atravessado definições que buscam esgotar aquilo que se busca definir, vislumbra-se um possível deixar-se à disposição imposto pela nossa própria singularidade quando nos engajamos no filosofar. Uma singularidade, ou subjetividade irredutível, nos termos de Eudoro, pressupõe sempre o outro, esta outra subjetividade irredutivel à minha. No caso presente, o outro, ao qual só tenho acesso pela disponibilidade a que me proponho neste texto, é o pensar estético de Eudoro, sua poética.

Para que fique claro que me distancio da busca por uma filosofia da arte e a fim de encontrar uma arte e um pensar que se querem o mesmo, seguimos o percurso aberto por Eudoro em Arte $e$ Escatologia. Neste ensaio afirma o filósofo que o elemento comum a toda obra de arte é a poesia. Haveria uma poesia da cor, outra da palavra e assim por diante. Se admitirmos que uma filosofia da arte busca sempre tentar estabelecer o que faz que uma obra de arte seja uma obra de arte, seria, sem dúvida, para Eudoro, no caráter poético da arte que se encontraria essa essência.

Uma filosofia da arte teria, portanto, a poesia por objeto. Mas é, justamente aí, nessa tentativa de objetivar a poesia, isto é, no esforço por definir o que é o puro fazer como algo de acabado, feito, que se encontra o limite de toda filosofia da arte. Em outros termos, se por um lado uma teoria filosófica da arte põe em evidência a poesia, ao tomá-la como limite da intuição da essência da arte, tal pensamento, por outro lado, localiza a poesia dentro dos limites de um discurso lógico-discursivo. 0 risco aí é o de reduzir a poesia à soma de atributos que a constituiria. Cai-se novamente na esfera de uma estética programática que tenta definir a poesia, subordinando-a a um discurso categorial. Parte-se da intuição do caráter poético de toda arte para, em seguida, abandoná-la em favor da sua descrição como objeto de análise.

Definindo o caráter poético como o belo, e o belo como aquilo que provoca prazer estético, com efeito, aponta Eudoro, encontramo-nos em um círculo vicioso. Para sair de tal situação, contudo, não há outro caminho a percorrer senão aquele já aberto pelo pensamento lógico-discursivo. A ideia é de mantermos justamente em mente que tal discurso é processo, caminho, ou melhor, encaminhamento que damos ao pensar. Processo que nunca encontra fim, mas que para ele tende. 0 pensar assemelha-se, assim, a uma série matemática infinita, cujo limite é a soma dos termos para onde estes convergem, sendo que nenhum ponto da série deve ser tomado como ponto final.

[...] só quando se detenha em qualquer ponto do infinito caminhar (representado pela infinidade dos termos da série), ou em qualquer estágio do infinito esforço por atingir a intuição da essência (limite da soma do infinito número de termos) é que o pensamento discursivo, na sua parcialidade, não equivale à verídica totalidade da intuição. (SOUSA, 2004(1), p. 154)

Para Eudoro, a distância entre o limite e a soma dos passos da caminhada do pensar, isto é, do seu encaminhar, nunca se esgota e constitui a própria medida da transcendência. Descortina-se, portanto, desde o início de Arte e Escatologia, uma observação acerca da essência mesma do pensar. Além disso, na recusa de uma estética tradicional que procura subordinar ao conceito de "prazer estético", os gêneros de atividade artística e seus atributos convencionais, encontra-se o delinear da essência da poesia, pois o transcender seria o campo da experiência próprio à arte. Para escapar então a um círculo vicioso imposto por uma definição esgotante da poesia, ou melhor, do belo como categoria da poesia, Eudoro sugere que o "prazer estético" ligado ao belo deva ser entendido como o nome que se dá a uma certa convulsão de sentimentos e emoções. Tal convulsão, segundo Eudoro, significa, ou melhor, é o sinal, de uma realidade sui generis que se apresenta na obra e pela obra. De fato, este 
"prazer" consiste em algo de sutil, aquilo que 0 poeta chamou de "leve diferença na alma". Cabe perguntar então o que na leve diferença da alma se transcende? Com certeza a esfera da banalidade, do banal lidar com as coisas no interesse operacional que elas podem ter.

Não há nesse transcender, entretanto, nenhuma sugestão do apagamento do mundo imanente, das coisas hodiernas, nem do esquecimento do homem na sua finitude. Pelo contrário, se efetivamente esse transcender se dá como processo e não como fim, nele se encontra a passagem para uma singularidade extrema em um instante extremo nesse mundo mesmo da banalidade ao qual pertencemos. Só em um pensamento instrumental que classifica os entes é que o Mundo, como categoria abstrata e o Homem como entidade genérica, assim como as coisas ou objetos, aparecem separados, desligados em sua essência. Religar, ou ligar é propriamente 0 ato de transcender as distâncias entre os entes, de eliminar os hiatos categoriais, de esgotar o que nos esgota, ou seja, esse Mundo e esse Homem reíficados.

0 mundo dividiu-se em dois, isto é, algo de inevitável, por efeito do projeto epistêmico, ético, estético, político, e assim por diante, constitutivos da modernidade. De um lado configura-se o reino da banalidade, do outro o da excepcionalidade. A arte situa-se como passagem entre os dois. Para cá da obra de arte vemos o que aparece como sendo o que aparece, para lá vemos o que aparece mais do que parece. 0 que seria isso que aparece mais do que parece através da poesia?

Com tal pergunta retoma, Eudoro encaminha 0 pensamento agora na direção do que se acostumou, desde Platão, a denominar o domínio da arte imitativa, isto é, o campo do ilusionismo, da imitação do imitado. Se a arte se faz desde os gregos como imitação, perguntar pelo que aparece mais do que parece através da poesia, ou seja, perguntar pela essência da arte, significa ter que retomar esta pergunta do ponto de vista do primado da imitação na arte ocidental. Dessa maneira, se a arte imita o que parece, ela nada mais é que cópia, repetição, reprodução especular. Se, contrariamente, ela é pura criação no sentido de não fazer referência a algo já dado no mundo, então se perde todo o lado da materialidade e da tradição contido na obra. A saída para esse dilema, entretanto, mostra-nos Eudoro de Sousa, já havia sido apontada por Aristóteles na sua poética. A atitude deste pensador em relação a Platão, seu mestre, seria antes a de uma correção, do que a de um afastamento radical, no que diz respeito à teoria da imitação na arte. 0 extremismo viria com as interpretações posteriores na modernidade. A arte imita sim, mas o que ela imita, na poesia é a natura naturans e não a natura naturata, diz-nos Eudoro.

Em nota ao capítulo 9 da sua tradução da $P o$ ética, Eudoro comenta a afirmação de Aristóteles de que a poesia é algo de mais filosófico e mais sério do que a história. Suspeito que este comentário junto com um outro sobre o capítulo 7 da referida obra são de suma importância para se compreender não só o que é a essência da arte, mas também o que é o próprio pensar de Eudoro, dentro dos termos que estou propondo, ou seja, como uma poética. Diz o filósofo helenista: “Na poesia, o "universal" consiste em narrar não o que aconteceu, mas o que poderia acontecer - o que é possível acontecer segundo a verossimilhança e a necessidade. A oposição entre poesia e história exprime-se agora pela oposição entre o acontecido e disperso no tempo (história) e o acontecível, ligado por conexão causal (poesia)." (SOUSA, 1986, p. 168).

0 acontecível é, assim, o que a poesia imita, o que ela deixa aparecer para além do parecer. A narrativa do acontecível excede o âmbito da história, isto é o do acontecido. No comentário ao capítulo 7, vemos que "o mito, o elemento mais importante da imitação poética, é determinado como totalidade e unidade e, portanto, diz Eudoro, vem a ser "coisa mais filosófica" do que a história. No mito, encontra-se mais o universal, que é objeto próprio da filosofia, do que o particular, ao qual se cingiria a atenção indagadora da história." (idem, p. 170). 0 acontecível é o necessário e universal. 0 mito é o seu dizer na poesia. Assim, a natura naturans ou a origem é aquilo que o mito narra, ou seja, o acontecível. A originalidade do acontecível, seu ser original é o que nos aparece como sendo mais do que parece na arte. “A imitação poética e artística, é-0, não dos entes originados, mas da própria origem dos entes". (SOUSA, 2004(1), p. 158). 
Entre as diversas passagens exemplares da relação entre originado e origem, a do prefácio de Sempre o Mesmo acerca do Mesmo chama a atenção pela ênfase no caráter atemporal da origem e pelo exemplo retirado de um gesto banal.

0 "originado" pode considerar-se sincrônica ou diacronicamente: mas a "origem" do originado, só ucronicamente. A origem preside tanto ao início quanto ao meio e ao término do originado que nos apareça via processionis. Quer dizer, a origem e o originado não podem situar-se no mesmo plano ou nível de realidade. Onde está a origem de uma linha traçada neste quadro? Traçada horizontalmente da esquerda para a direita, no primeiro ponto a esquerda? Ou no movimento do braço que a traçou? Não se confunda "inicio" (que pertence ao processo) com "origem" ( que ou permanece fora dele ou é inerente a todo ele)!" (SOUSA, 2004 (2), p. 155)

A ênfase aqui está em desfazer a confusão entre um início, o começo de uma série e a origem. Confusão que só o horizonte da banalidade instaura. 0 pensar proposto por Eudoro, pelo contrário, situa-se em uma proximidade com a origem. Por ser mitosofia, ele se constitui necessariamente, por conseguinte, em um narrar, um dizer poético, no qual o tema que surge na narrativa é o mito. Observe-se que o "tema" da filosofia ou da poética de Eudoro ou de qualquer poética não reside na narrativa da origem ou das origens. No narrar de um mito, é que a origem deixa aparecer a si mesma como a verdade do mito. Verdade aqui tem o sentido pensado por Heidegger de duplo movimento inscrito no desvelar e velar que preside a todo ser dos entes. 0 mito por sua vez, não é biografia de deuses, mitologia. Genealogia divulgada pela tradição, coletânea de lendas.

Mito é ontofania, ou ainda, para mencionar a formulação consagrada por Eudoro de Sousa, uma cosmofania teocríptica. Da morte de um deus surgem mundo e homem. Logo, esta ontofania é cosmofania e antropofania. No velar de um deus, ousaria dizer, desvela-se um mundo e inversamente no velar de um mundo desvela-se um deus. Mitosofia, portanto, caracteriza-se por um empreendimento maior, mais original, do que história de mitos. Mitosofia é o pensar que se expande em diversas direções que abrangem o homem e o mundo na sua relação com 0 originário. Dentro desta perspectiva e admitindo-se que mito é o dizer da poesia, o que seria a arte senão mitosofia? Um fazer poético, um pensar da poiêsis no qual o originário se deixa entrever.

Mito é teocríptia. Um deus só aparece, só o é no ser alegoria da origem. Alegoria é dizer 0 mesmo no outro ou pelo outro. Mas há certamente este instante em que um deus, assevera Eudoro, uma ofuscante fulguração, nos cega. Ele deixa-se entrever nas coisas, no outro, ao mesmo tempo em que nelas se oculta. Isso significa, ainda que seja só fulguração, que sempre há possibilidade do encontro com um deus, no sentido de origem, com a condição de nos deixarmos estar nessa singularidade descrita como a subjetividade irredutível. 0 encobrimento total do divino, seu desaparecimento, é próprio apenas de um Mundo e de um Homem hipostasiados nas suas categorizações. Ofuscante, o deus é mistério. Mistério, afirma Eudoro, é a categoria que a arte compartilha com o religião.

Mistério, entretanto, não tem, aqui, a acepção de enigma, algo a ser resolvido, solvido ou dissolvido. Ele é sentimento que é da ordem do inefável. Não se diz o mistério, não é possível dizê-lo porque, simplesmente, ele excede o conformar-se à linguagem. Na sua origem etimológica mistério refere-se à condição do iniciado que deve manter o segredo da iniciação. Contudo, se a arte consiste, em grande parte, em arrancar da obscuridade um mundo, em outras palavras, dar forma ao informe, não implicaria isto - na medida em que a poesia mostra mais do que parece - 0 abandono do mistério na arte em função de um prazer estético? Abandonar o mistério da arte seria abandonar a própria dimensão do poético que a faz arte, para torná-la, simultaneamente, objeto de interpretação e coisa que interpreta. Pelo contrário, do caráter misterioso da arte surge uma luz outra que não aquela da qual depende a razão lógico-discursiva, luz que clareia e esclarece. A luz da poesia é a da obscuridade, luz noturna única capaz de, nas palavras de Eudoro, tanger as cordas da sensibilidade e da emoção.

Assim, a arte explica e não se explica, não se deixa capturar em categorias estéticas ou discursivas, mas explica tais categorias, coloca-as como 
categorias que elas são e retorna à origem. Assim também, as coisas encontram seu lugar na obscuridade ofuscante da linguagem poética. Para nos falar desta linguagem mitopoética, recupera Eudoro a oposição entre tautegoria e alegoria de Schelling, mas a recupera como relação complementar. No falar poético, o mesmo e o outro aparecem sempre como o mesmo, ou seja, como tautegoria. 0 que poetiza a poesia desvela-se nesse poetizar, ultrapassando a banalidade do ser mero conceito, noção, signo de algo, apetrecho conceitual ou físico nos termos de Heidegger. Ela se opõe àquela linguagem, cuja essência é o uso sistemático no determinar, no descrever e definir as coisas no seu aparecer como sujeito e predicado da proposição.

Por isso, Eudoro retoma o exemplo das botas de Van Gogh já pensada por Heidegger e diz: “Enigmático não é o quadro, Misterioso, sim; que botas daquelas não calçaram nem jamais calçarão pés calcorreando o mundo da banalidade." (SOUSA, 2004 (1), p. 159.). A poesia do quadro de Van Gogh não consiste em descrever ou representar um par de botas. Ali vige o par de botas no "por-se-em-obra-da-verdade-do-ente" que Heidegger identifica na Origem da Obra de Arte como o ser da arte. (HEIDEGGER, 1990, p. 27). Só na verdade da arte é que podemos ter acesso ao ser dessa coisa banal, o par de botas, este objeto utilitário,. A essência da arte, para Heidegger, estaria muito mais na Verdade, no sentido da Alethea, o velar/desvelar do ser do que em uma verdade que se quer adequação entre proposição e objeto.

Este desvelar/velar, contudo, vige na representação da coisa representada. Seja na linguagem verbal, seja na imagem pictórica ou em outro tipo de representação qualquer, a arte imita a originalidade da coisa representada, quer dizer, sua natureza, (physis). Originalidade deve sempre ser entendida, para além da ideia do novo, como algo que revela a si mesmo na sua origem. Não tem nada a ver com a ditadura do novo, da novidade de algo que pretende sempre significar o diferente. Trata-se, nesse ponto, portanto, de colocar em relevo o caráter simbólico da arte, diferenciando de uma função denotativa ou de significação. Arte não significa, mas simboliza.
Levando em conta a complexidade do que venha a ser símbolo no pensar de Eudoro, devo contentar, neste texto, com uma breve tentativa de capturar o seu sentido, sem entretanto perder de vista a centralidade que o simbólico tem aqui, posto que é a partir dele que se esboça a compreensão de um outro tema caro a Eudoro, aquilo que ele denomina horizonte. Significar implica sempre uma coisa que significa outra, enquanto simbolizar é o aparecer daquilo que se simboliza no símbolo mesmo. No símbolo que é toda arte algo revela-se em si mesmo sua origem, ou seja, não a coisa feita, mas o fazer-se coisa. Símbolo é, por conseguinte tautegórico. Já o signo permanece no âmbito do alegórico. Como nos lembra a etimologia da palavra alegoria é o "querer dizer outra coisa" que não aquela que ficou expressa. Símbolo, explica Eudoro, “designava um objeto dividido em dois pedaços, que, uma vez reunidos, provavam certa relação entre seus portadores, verbi gratia, os deveres de hospitalidade outrora exercidos por um em relação ao outro." Só na união simbólica é que as partes tornam-se um todo, continua o filósofo. “Nenhum símbolo é coisa, nem qualquer de suas partes, se, na verdade faz parte de um todo. 0 símbolo é o "todo"." (SOUSA, 2004 (3), p. 107).

Se coisa há que adquire significação e sentido na obra de arte, esta não the é externa. Insisto: para Eudoro a arte não interpreta, não descreve ou representa entes, mas sim simboliza. Ela deixa vir na vigência da coisa o ser como o próprio vigor das coisas. Interpretar é alegorizar esquecendo-se do tautegórico que na alegoria se vislumbra. É colocar-se, assim, na unilateralidade de um horizonte de coisas no qual vige o separar. Neste horizonte Mundo e Homem são coisas entre coisas. Este é o horizonte que Eudoro denomina de diabólico. Oposto ao simbólico está o diabólico. Na sua origem Diabólico quer dizer "qualidade inerente ao separado" explica Eudoro.

No entanto há dois tipos de separação: a divina e a diabólica. Uma separa no desvelar/velar do Ser, a outra fecha e não abre 0 acesso à unidade do Ser no qual estariam simbolicamente reunidos 0 homem, o mundo e o divino. 0 princípio que rege 0 simbólico é o Eros, do qual participam arte religião e 
filosofia, ou mitosofia. Na esfera do diabólico impera o ter, o possuir que implica a fragmentação e coisas que reproduzem coisas. Ao buscar possuir somos possuídos pelas coisas, ao nos servirmos delas, por serem apenas coisas, tornamo-nos coisas a serviço de coisas. A relação que se estabelece entre coisas dá-se na ordem das classificações sistemáticas feitas pela razão que classifica e ordena com vista a um fim determinado. “Diabólica é a fatal e irremediável fragmentação de tudo em "coisas" que só podem relacionar-se pelo lado de fora [...]" (idem, p. 93). $\mathrm{Na}$ ordem de uma racionalidade lógico-discursiva e de uma instrumentalização de todos os âmbitos da vida, faz-se necessário, para que as coisas permaneçam coisas, evitar todo o entrelaçamento, toda mistura, evitar o diluir dos limites exatos que delimitam as coisas e as colocam em relação; pois nem o oposto que pressupõe o que está posto encontra lugar no diabólico.

0 princípio, dizíamos, que rege o simbólico é o Erótico. Ligados, eroticamente, os entes vivem como um só. Do mundo das coisas o Eros desertou, diz Eudoro. ${ }^{1}$ No mundo diabolizado, há sempre um fim em vista, um algo a ser alcançado, um patamar a ser galgado. Regido pela vontade e pelo intelecto reduzidos à norma da reprodução do trabalho e do discurso que legitima este trabalho, nunca o homem pode distrair-se.

Obviamente, Eudoro, não está pensando aqui no lazer, nos divertimentos que compõem com o ritmo do trabalho mecânico, cuja necessidade única consiste em reproduzir-se em todas as dimensões da vida. A distração do trabalho é um preocuparse, um colocar-se em um estado de atenção, com relação à saúde, à forma física, à necessidade de descontrair-se por exemplo. No lazer o homem está também concentrado, ele faz coisas, pensa coisas, pensa em si como coisa que deve divertirse. A distração seria, para Eudoro, pelo contrário, o primeiro encaminhamento para fora da esfera do diabólico. Ainda que jamais possamos passar para o além da dimensão do banal repetitivo e produtivo, podemos transcendê-lo em um horizonte no qual vige o simbólico. Na distração estamos fora de nós mesmos, perdidos, mas apenas para o horizonte diabólico. Distanciamo-nos de toda premeditação e nos colocamos à disposição para o aceno dos deuses. Como me lembrava o filósofo Fernando Bastos, em conversações pessoal, deuses são as forças plasmadoras da cultura e da história.

Distraídos nos furtamos a uma visão atenta e interessada das coisas. 0 que distrai o distraído é o amor, o elemento erótico. Mas como distrair-se? Como colocar-se à desatenta disposição necessária para se receber o aceno dos deuses, isto é, o aceno que vem da origem? Em outras palavras de que maneira acontece esse deixar-se estar em uma abertura em que o poético, o mito vige? A resposta, parece nos indicar Eudoro de Sousa, reside naquilo que a arte compartilha com a religião, quer dizer, no mistério e mais precisamente no êxtase erótico-religioso ${ }^{2}$. Este tipo de êxtase traz uma experiência da união que revela o distrair em um sentido ontológico. No estar fora de si do êxtase, diz Eudoro, “há um perder-se daquilo que veio a ser, para ganhar no que o outro nunca foi, e que também de si mesmo se perdeu, o ser que envolve a ambos, num amplexo que transcende toda a individuação." (SOUSA, 2004 (3), p. 95).

0 que está em jogo aqui é o morrer. Morte e êxtase estão ligados. Morte deve ser pensada na acepção de metamorfose do iniciado, daquele que presenciou o mistério. Metamorfose no sentido de katábasis de descida aos infernos. A minha metamorfose é também a do mundo. "Se me enviam em outro início, se me fazem passar outro limite, se, pelo início e pela passagem, mudo de forma, da mesma forma de forma o mundo muda; mas se iniciado me ultrapassei, sou outro que não era, e outro é o mundo em que vim a ser outro" (idem, p. 91).

Quem me envia? Que outro limite é este que devo passar? Com estas questões e a partir desta belíssima passagem de Eudoro, gostaria de introduzir o tema dos horizontes caro ao seu pensar, e que se revela fundamental no plano da poesia. Horizontes não são metáforas, categorias, imagens para explicar as diversas dimensões da experiência do Ser. Arrisco uma quase definição: Horizonte é mito, no sentido de originário e como tal, constitui o Ser. No delírio extático, o homem atravessa a presença do presente do horizonte objetivo, coisificante, diabólico - 0 horizonte do mundo cotidiano e ordinário - para o
1. “As coisas residem todas elas, num deserto da suprema afeição; coisas não se afeiçoam, nenhuma quer tomar a feição de outra, de contrário, deixariam de o ser. No que o Erótico insiste, as coisas resistem. Enquanto forem coisas, sempre dois entes que se amem ou fulgem amar-se permaneceram separados." SOUSA, Eudoro de. Mitologia e História e Mito, Lisboa, Imprensa Nacional, 2004, p. 91

2. Quatro êxtases ou loucura mencionados por Platão: profético, teléstico (iniciático) o poético e 0 erótico são relacionados às 3 manifestações do espírito Absoluto Hegeliano. Profético e teléstico reúnem-se na manifestação religiosa, loucura poética na poesia, arte e a loucura amorosa ou erótica na manifestação filosófica. 
horizonte trans-objetivo mediador e simbólico. Este horizonte trans-objetivo é o da poesia, isto é, do mito. No horizonte trans-objetivo, a expressão do mito não é explicativa, mas simbólica e por isso, poética. Neste horizonte, o mito é tautegoria e promove uma inteligibilidade sensível do que pode ser vislumbrado do além-Horizonte ou Horizonte extremo, no aquém-Horizonte.

Portanto, são três os horizontes que constituem o Ser, sendo que o aquém horizonte, aquele da objetividade operacional é também o limiar do outro, o da trans-objetividade. Os horizontes se instituem e se ligam em uma relação de complementaridade, logo pertencem à ordem do simbólico, ou seja, a um todo complementar que une os opostos no mesmo, na vigência de uma tautegoria. Entretanto, observa Eudoro: “A Tautegoria do impulso mítico, criador de mitos, tão tautegóricos quanto o impulso, não dispensa a alegoria, não dispensa que se diga uma coisa que outra quer dizer. 0 decisivo, em mitologia, não é banir o alegórico. É fazer que no állo (outro) se mostre o tautó (mesmo)." (SOUSA, 2004 (3), p. 52). Ou seja, é na diferença entre alegoria e símbolo que se encontra a medida da transcendência da arte.

Horizontes não limitam espaços, mas indicam um centro. Assim, ao pensarmos o ser poeta, como katábasis, o descer aos infernos, segundo Eudoro, quero crer, que não nos livramos do aquém horizonte no horizonte trans-objetivo, mas convergimos para um centro. Não o ultrapassamos atravessando a trans-objetividade para assim atingir o alémhorizonte, pois aí já não haveria mais horizonte, já não mais haveria o Ser, mas apenas a excessividade Caótica, o abismo sem fundo, na expressão de Eudoro. Apenas no simbólico, que se instaura no e pelo alegórico, delimita-se aquele centro do qual os horizontes são os limites liminares. Não um centro geométrico, topológico, mas existencial vislumbre do originário originante de todo originado. Dessa maneira, o dar-se no centro de todo horizonte, o encontrar simbólico do Horizonte trans-objetivo, faz-se necessário o descer aos infernos.

Descida aos infernos, para além de tudo o mais que possa significar ( um símbolo não se deixa cingir de um só relance), significaria a transposição do último horizonte que envolve todo o campo da experiência comum. Que todo o poeta, que todo o artista de gênio alguma vez ultrapassou esse horizonte; que toda a poesia, que toda a arte, nos traz mensagens dos infernos - lá onde as coisas têm a origem primeira e o termo final -, não sabemos quem o possa duvidar. (SOUSA, 2004 (1), p. 164)

Gostaria de encerrar sem finalizar objetivamente este percurso de uma aproximação ao pensar de Eudoro, sua mitosofia, com uma indagação: não seria o trazer as mensagens dos infernos, lá onde as coisas tem a origem, a mensagem maior que nos lega Eudoro do que seja a tarefa autêntica da filosofia? Este encaminhar-se poético e distraído para a proximidade erótica dos vestígios do horizonte profundo que, simbolicamente, emergem no horizonte aparente.

\section{REFERÊNCIA BIBLIOGRÁFICA}

HEIDEGGER, M. (1990). A Origem da Obra de Arte. Lisboa, Edições 70 .

SOUSA, Eudoro de (1986). A Poética, tradução prefácio, introdução, comentário e Apêndices de Eudoro de Sousa. Lisboa, Imprensa Nacional.

(2004 (1)). Arte e Escatologia in Dioniso em Creta. Lisboa, Imprensa Nacional.

(2004 (2)). Horizonte e Complementaridade, Sempre o Mesmo acerca do Mesmo. Lisboa, Imprensa Nacional

(2004 (3)). Mitologia e História e Mito. Lisboa, Imprensa Nacional.
Recebido em novembro de 2011. Aprovado em dezembro de 2011. 